\title{
EVALUATION OF THE USE OF THE PEDIATRIC SYMPTOM CHECKLIST AS SCREENING FOR EMOTIONAL AND PSYCHOSOCIAL PROBLEMS IN A PUBLIC SCHOOL IN CURITIBA, BRAZIL (ABSTRACT)*. DISSERTATION. CURITIBA, 2008.
}

\author{
SANDRA REGINA BAGGIO MUZZOLON**
}

Introduction: The identification of emotional and psychosocial problems must be part of the pediatric practice. Studies have documented the increase in the prevalence of Mental Disorders in children and adolescents. Even so pediatricians still have not received adequate training on this subject. The routine use of emotional and psychosocial assessment tests has been proposed as a way to improve and thus increase the recognition of problems, enabling the early initiation of appropriate intervention.

Objective: To investigate the effectiveness of the Brazilian version of the Pediatric Symptom Checklist (PSC) as a tool at screening for the identification of emotional and psychosocial problems and their prevalence in a population of children and/or adolescents aged between 6 and 12 years, attending the fundamental level in a public school in the city of Curitiba, PR.

Method: In the first stage of study, the PSC was answered by 415 parents and/or responsible person for the students with an average age of $9.21( \pm 1.99)$, taking the elementary schools, of which, later, 145 responded to PSC and Child Behavior Checklist, $\mathrm{CBCL}$ questionnaires.
Results: From the initial population of the study, 14\% showed POSITIVE result for the PSC, indicating frequency of response to psychosocial problems, ie value $\geq 28$. In the sample the prevalence of PSC POSITIVE was $34 \%$. The consistency of the PSC Brazilian version was good (Cronbach alpha 0.89). The ROC curve showed the better cut-off at 21 , with sensitivity of $96.8 \%$ and specificity of $86.7 \%$. In the cut point ( 28 and above) it was observed sensitivity of $64.5 \%$ and specificity of $100 \%$, similar to the results found in the American version indicating similarity between the Brazilian and American samples. The male gender prevailed in the group with indicative of psychosocial dysfunction. The PSC proved to be appropriate for the age group studied, with more sensitivity and specificity in children below 10 years of age.

Conclusion: The Brazilian PSC version proved to be an effective tool in the early identification of emotional and/ or psychosocial problems in a group of children and/or adolescents at school age.

Key words: pediatric symptom checklist, early identification, mental disorders.

*Avaliação do uso da Lista de Sintomas Pediátricos como um instrumento para a triagem de problemas emocionais e psicossociais para uso na prática clínica do Pediatra. Dissertação de Mestrado, Universidade Federal do Paraná (UFPr) (Área: Saúde da Criança e do Adolescente). Orientador: Lúcia Helena Coutinho dos Santos.

**Address: Petit Carneiro 1083 / 401 - 80240-050 Curitiba PR - Brasil (E-mail: sandramuzzolon@terra.com.br). 